\title{
EMB Charger and MPPT Merging in Micro-Satellites
}

\author{
B. Abdi, S. M. M. Mirtalaei, and R. Ghasemi, Member, IACSIT
}

\begin{abstract}
Life time of chemical batteries is one off main problems in low earth orbit satellites due to their fast charge and discharge. Electro-mechanical batteries have some important advantage in comparison with chemical one, but they need a 3 phase, variable voltage and frequency, inverter. The method of maximum power point tracking in satellites utilizing electro-mechanical energy storage systems are proposed in this paper. It will be shown that efficiency and reliability is increased in the proposed manner.
\end{abstract}

Index Terms-MPPT, energy storage, electromechanical, battery.

\section{INTRODUCTION}

Electrical power system always has been an important issue in satellite applications. Satellites can be categorized to Geostationary Orbit (GEO), Low Earth Orbit (LEO) and Medium Earth Orbit (MEO) satellites [1].

LEO satellites take place at 300 to 1000 kilometers orbits from the earth [1], [2]. Due to short distance from the sun, LEO satellites require low power. Therefore, usually their entire energy is supplied from sun light. On the other hand, most of these satellites spend a part of their rotational period in eclipse. So, an energy storage system is inevitable to keep them alive in eclipse duration.

Energy storage systems of LEO satellites were only chemical batteries until the late of 90th decade till NASA employed them in the international space station [3], [4]. The most important problem with batteries is the limitation of their charge and discharge cycles which shorten their lifetime and performance [5]. LEO satellites have a period of 1.5 to 1.74 hours respective to their orbit, so the rate of charge/discharge is very high and this reduces batteries lifetime down to 3-5 years [5].

In 1976, Dr. Kirk from Maryland University and NASA proposed an investigation on application of flywheels as energy storage systems in satellites [6], [7]. They are rather to be built with high radius and work in high speed to store more energy instead of having high weight. Advantages of flywheel energy storage system or electro-mechanical batteries (EMB) are presented in [3]-[6]. Unlimited charge/discharge cycle as well as the satellite lifetime, higher efficiency, higher energy density, higher discharge depths, thermal independency and their usage in attitude control of satellite can be mentioned as some of these advantages.

Manuscript received January 23, 2013; revised May 18, 2013.

This work was supported in part by Damavand Branch, Islamic Azad University.

The Authors are with Damavand Branch, Islamic Azad University, Damavand, Tehran, Iran (e-mail: babakabdi@ieee.org).

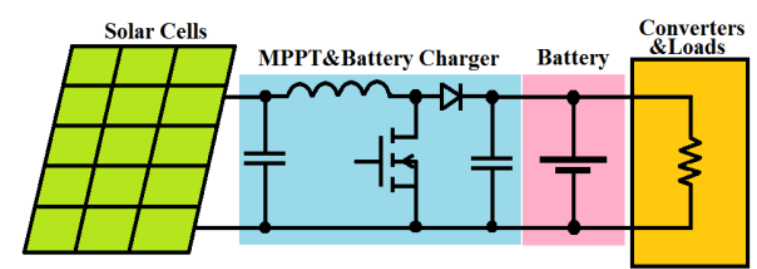

Fig. 1. Electrical power subsystem in a LEO satellite.

On the other hand, LEO satellites achieve their electrical using solar panels energy from the sun. The effective area of solar panels is limited in satellite application in addition to their expensively. In a satellite photovoltaic system, the PV panel represents the most percentage of the total cost of the system, the battery storage system second expensive block and other system components such as power electronic inverters and converters contribute only a small percentage of system cost. Due to the high cost of solar cells, it is necessary to operate the PV panel at maximum power point (MPP) [8]. Therefore, a DC-DC switching converter or maximum power point tracker (MPPT) is necessary for impedance matching between solar cells, loads and energy storage system in the charge and discharge states. Fig. 1 shows a block diagram of electrical power generator section in a LEO satellite. The MPPT converter is serried with solar cells and all of produced power has to be processed in MPPT and multiples by efficiency of MPPT. MPPT converter can also control charging rate of battery.

Buck, boost, buck-boost and flyback are most common topologies [8]-[13] and Perturbation \& Observation (P\&O) is the common algorithm for MPPT converters [13].

MPPT converters can be serried or paralleled with loads. The parallel method has more overall efficiency [14]. Using two MPPT and flywheel charge/ discharge converters cause lower efficiency, more complexity and thermal problems and finally lower reliability.

In the case of using EMB as satellite energy storage, MPPT converter must paralleled with DC bus voltage because of wide voltage variation range. A bidirectional DC-DC converter and three phase inverter needs for charge and discharge states. About all previous works focused on chemical battery based MPPT.

The method of MPPT and charge/discharge conversion in an EMB based satellite energy storage system is presented in this paper. Control algorithm presents according satellite states. Load feed-forward signal uses for fast direction change and more stability.

The basic concepts of EMB and MPPT operation are given in II and III. The manner of their merge and control algorithm are discussed in IV and chapter V is conclusion of the paper.

\section{EMB CONCEPTS}

Fig. 2 shows an EMB. Electrical energy converts to kinetic 
energy in the charge duration and flywheel speeds' increase until maximum allowable speed which determined by mechanical limitations. Stored energy on flywheel, En, calculates using equation (1) [15].

$$
E_{n}=\frac{1}{2} I_{\text {total }}\left(\omega_{2}^{2}-\omega_{1}^{2}\right)
$$

where $I_{\text {total }}$ is flywheel inertia and $\omega_{1}$ and $\omega_{2}$ are maximum and minimum allowed flywheel speed respectively.

Maximum speed of rotation is kept as high as possible for mass and volume optimization. Rotational speed kept between 20000 and $60000 \mathrm{rpm}$ in satellite application [15], [16].

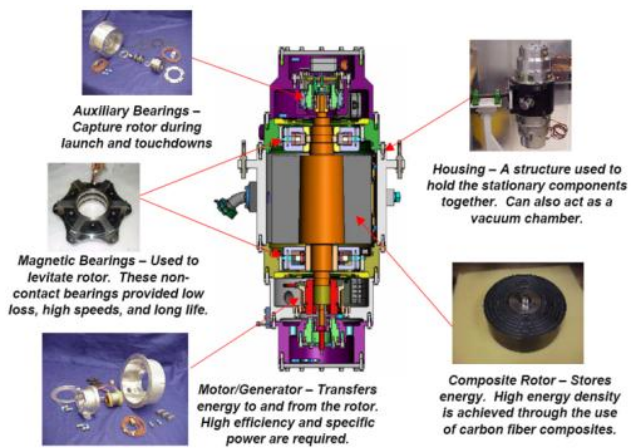

Fig. 2. An electro-mechanical battery [1].

The most important part of an EMB is the electrical machine, which is used as Motor/Generator for energy conversion. Brushless DC (BLDC) machines are mostly used in EMBs because of having high torque to weight ratio, low rotor losses, high efficiency and brushless ness [17], [18]. The speed of flywheel is varied up to three times to achieve the proper depth of discharge [15]. In BLDC machines, voltage of output terminals is proportional to rotor speed, so, the output voltage varies more than tripled and proper DC-DC converter topology has to be selected.

On the other hand the terminal voltages can be controlled using drive (or inverter) system as well as its' current. So, BLDC machine can works in motor or generator mode.

\section{MPPT CONCEPTS}

In a satellite photovoltaic system, the PV panel represents the most percentage of the total cost of the system, the battery storage system second expensive block and other system components such as power electronic inverters and converters contribute only a small percentage of system cost. Due to the high cost of solar cells, it is necessary to operate the PV panel at maximum power point (MPP). The maximum power produced by a solar cell changes with solar radiation and temperature as shown in Fig. 3 and Fig. 4.

In order to optimize the ratio between output power and cost of installation, photovoltaic systems are supposed to draw maximum power from the modules continuously, regardless of weather conditions or load voltage. Maximum power point trackers, commonly known as MPPT, are systems that operate PV modules so that maximum power can be achieved in all radiation and temperature conditions. Fig. 1 shows a PV system include MPPT.

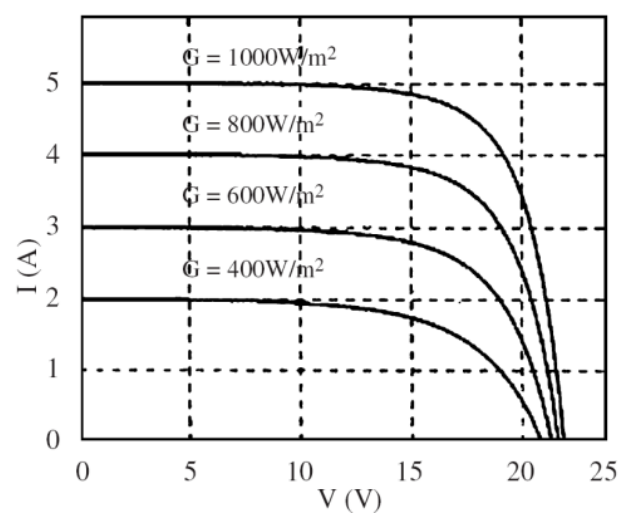

Fig. 3. Power generation in a solar cell versus solar radiation.

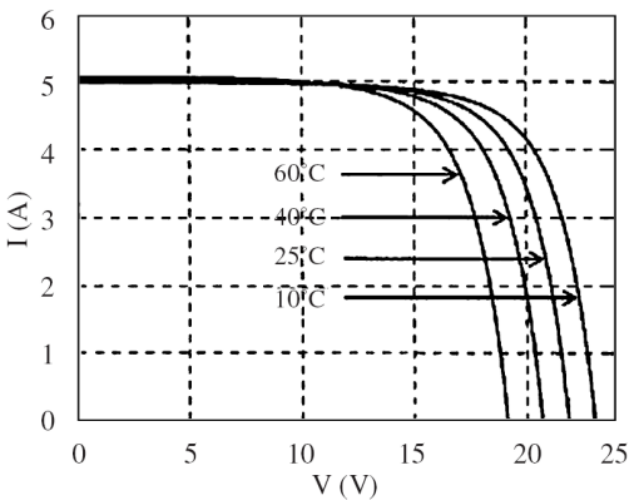

Fig. 4. Produced power in a solar cell versus temperature.

Different topology of DC-DC converters are used as MPPT. The DC/DC conversion process implies in turn an associated effect of impedance transformation, i.e., the input impedance shows a dependence on a number of parameters such as load resistance, duty cycle, etc. In this sense, converters are similar to transformers. When they are used as impedance adaptors, except that in converters the adaptation parameter is not the turns ratio between the secondary and primary ones, but the duty cycle $\mathrm{D}$, which can be governed electronically, a fact that corresponds to MPPT. Comparison between different topology of converters for MPPT operation is given in [8]-[12]. Buck and Boost are suitable topologies for satellite application.

\section{PROPOSED CIRCUIT}

Before you begin to format your paper, first write and save the content as a separate text file. Keep your text and graphic files separate until after the text has been formatted and styled. Do not use hard tabs, and limit use of hard returns to only one return at the end of a paragraph. Do not add any kind of pagination anywhere in the paper. Do not number text heads-the template will do that for you.

Finally, complete content and organizational editing before formatting. Please take note of the following items when proofreading spelling and grammar:

\section{A. Power Electronic Circuit}

Proposed circuit is shown in Fig. 5. A bidirectional DC-DC converter (BDC) is used for EMB and DC bus 
interconnection. It works as boost converter in the charge state and increases DC bus voltage to suitable level for EMB. In discharge state it works as buck converter. It decreases and stabilizes DC bus voltage to appropriate level for loads' DC-DC converters.

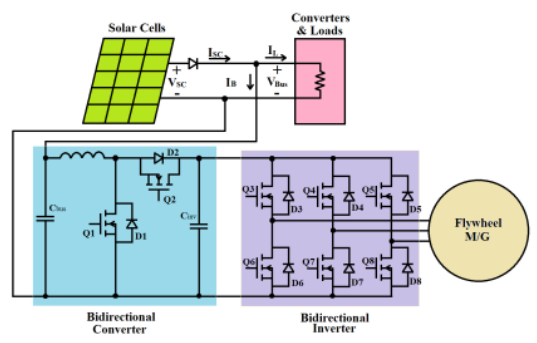

Fig. 5. Electrical power subsystem of a satellite including EMB energy storage system (proposed circuit).

Output voltage of this converter or input voltage of three phase inverter is controlled based on flywheel speed and electrical machine state (motor/Generator), from 30 to 95 volts. In the charge state, Q1, D2, L and $C_{i n v}$ constitute boost converter. Relation between input voltage, $V_{b u s}$, and output voltages, $V_{i n v}$, calculates by Eq. (2) [19].

$$
V_{i n v}=\frac{1}{1-D} V_{B u s}
$$

where $D$ is duty cycle, on time duration/switching period, controlled by control circuit.

Input voltage of BDC is controlled according Eq. (2), based on solar cell MPPT in charge state from 17 to 28 volts. It kept constant in discharge state at $35 \mathrm{~V}$ based on loads' converters more efficiency. In the discharge state, Q2, D1, L and $C_{b u s}$ constitute buck converter. In this mode, relation between output voltage, $V_{b u s}$, and input voltages, $V_{i n v}$, calculates by Eq. (3) [19].

$$
V_{b u s}=D V_{i n v}
$$

A bidirectional three phase inverter inverts the input DC voltage, $V_{i n v}$, to a variable frequency trapezoidal waveform adequate for BLDC machine and vice versa. Q3 to Q8 forms inverter during charge state and D3 to D8 constitute a three phase full bridge rectifier during discharge state.

\section{B. Control Algorithm}

Control circuit consist two main parts. The first one belongs to BDC. This section defines duty cycle of Q1during charge state based on MPPT calculations and EMB required $\mathrm{DC}$ voltage. Perturbation and observation $(\mathrm{P} \& \mathrm{O})$ algorithm is used for MPP tracking [13]. Charge current is controlled instead EMB's voltage because of its simplicity and better stability. So, solar cell's voltage and current, $V_{s c} \& I_{s c}$, and EMB current, IEMB, is measured for this aim. Howbeit EMB's voltage, VEMB, is sensed for full charge detection and over speed protection. The first section of control circuit also defines duty cycle of $\mathrm{Q} 2$ in discharge state according bus voltage, $V_{\text {bus }}$, stabilization against EMB voltage, VEMB, variations.

The second section of control circuit belongs to EMB's inverter. In the charge state, turn on and turn off of each inverter's switch, as well as output frequency, defines by position of flywheel which is sensed by three hall effect sensors. The amplitude of trapezoidal waveform controlled by BDC according EMB's allowed charge or discharge current. These switches are disabled during discharge state and diodes make a full bridge rectifier.

Fig. 6 shows variations of DC bus and inverter Voltages during a period of satellite rotation (a charge and discharge period).

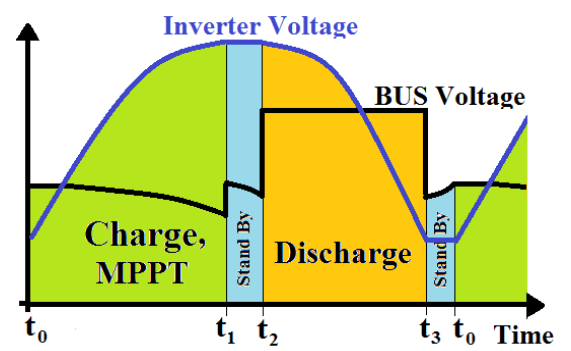

Fig. 6. Variations of DC bus and inverter voltages during a period of satellite rotation (a charge and discharge period).

The different parts of operation can be explained as follow:

T0-T1: In this moment satellite comes out of eclipse. EMB is discharged to allowable level and flywheel has minimum allowed speed at the moment of T0. Solar cells can produce power for supplying loads and charge EMB. Therefore, control circuit regulates DC bus voltage according MPPT. In fact DC bus voltage regulates according charge amount of EMB. If satellite consumption plus EMB charge amount is more than produced solar cell power, solar cells work at peak power (MPPT). Otherwise DC bus voltage regulates according charge current limitation. Clearly, direction of current is changed in the BDC and inverter. Assuming constant charge power, speed of flywheel increases according eq. (1). Terminal voltage is proportion with speed and increases accordingly.

T1-T2: BDC can't change direction of current instantaneously because of its inductor. So, if satellite consumption increase suddenly to a value more than produced power by solar cells, EMB cannot compensate their difference. So, DC bus voltage will collapse and satellite will restart consequently. To avoiding this problem, at $\mathrm{T} 1$, that generated power by solar cell is less than 1.2 times of satellite consumption; BDC changes its direction and stay standby for discharge state and power compensation of solar cells.

T2-T3: During satellite entrance to eclipse, generated solar panel power decreases and EMB starts to supply the satellite consumption. At T2, generated power, by solar panels, decrease to less than half of satellite consumption. Control circuit keeps the DC bus voltage higher than solar cells no load voltage. So, solar cells are eliminated and EMB supplies the satellite. Flywheel speed decreases to minimum allowed level. During this interval, DC bus voltage is kept in the highest level allowed by converters, for current minimization and converters efficiency optimization.

T3-T0: satellite comes out from eclipse at T3 but solar panels cannot supply all of its consumption. Therefore, control circuit decrease DC bus voltage level to $70 \%$ of solar cells no load voltage to operate about MPPT. EMB and solar cells will supply satellite together in this interval. At T0 generated power with solar cells increase to more than 1.2 times of satellite consumption, so, EMB charges and BDC works according MPPT. 


\section{DISCUSSION}

Comparison between traditional and proposed structure is discussed in this paper. A LEO satellite with 90 minute period, 60 minute at sun surf and 30 minute at eclipse, is assumed for this aim. The satellite consumes $40 \mathrm{~W}$ continuously, so, it needs 20wh energy storage system according its eclipse duration. Using traditional structure, shown in Fig. 1, and $80 \%$ energy efficiency for chemical battery (charge and discharge), $25 \mathrm{wh}$ has to delivered to the battery. Therefore, boost converter has to convert $65 \mathrm{w}$, and, it has $11.5 \mathrm{w}$ dissipation at charge state. Assuming $85 \%$ efficiency for this converter, solar cells has to generate $76.5 w$. Finally, chemical batteries designed for this satellite has $7.8 \mathrm{~kg}$ weight and $7700 \mathrm{~cm} 3$ volume.

In the proposed structure although generated power is delivered directly to load, but stored energy is processed twice at charge and discharge states. The designed EMB for this satellite has $95 \%$ efficiency, $1.2 \mathrm{~kg}$ weight and $600 \mathrm{~cm} 3$ volume [15]. Then, 22.1w needs for its charge. Assuming efficiency of $95 \%$ for inverter at charge state and $98 \%$ for rectifier at discharge state, $\mathrm{BDC}$ has to deliver $23.8 \mathrm{w}$ at charge state averagely. By assuming $85 \%$ efficiency for $\mathrm{BDC}$, the input power of energy storage system is $33 \mathrm{w}$ and solar cells have to produce $73 \mathrm{w}$.

BDC converts $40 \mathrm{w}$ at eclipse therefore its maximum dissipation is $6 \mathrm{w}$ at discharge state. According above discussion the following points can be resulted:

Weight and volume is decreased $84 \%$ and $92 \%$ respectively in EMB method.

Produced power with solar cells is decreased $4.5 \%$.

Nominal power of BDC is $38.4 \%$ less than boost converter in traditional structure.

Maximum dissipation in boost converter is $48 \%$ more than BDC which cause more thermal complexity as well as lower reliability [20].

\section{CONCLUSION}

The manner of maximum power point tracker and electromechanical battery charger proposed in this paper. The output voltage is too variable in electromechanical batteries because of their variable speed, so, in spite of chemical batteries, they have to be paralleled with DC bus including their charger, MPPT and inverter. It was shown that with proposed circuit weight and volume of electrical power subsystem are decreased considerably. Solar cell area and nominal power of MPPT also decreased, but, efficiency and reliability are improved.

\section{REFERENCES}

[1] Langley Research Center. [Online]. Available: www.larc.nasa.gov

[2] The Tech Museum of Innovation. [Online]. Available: http://www.thetech.org

[3] D. Christopher, R. F. Beach, and J. R. Barton, "A flywheel energy storage system test on the International Space Station," NASA Lewis Research Center, 1996.

[4] P. E. Kascak, B. H. Kenny, T. P. Dever, W. Santiago, and R. H. Jansen, "International space station bus regulation," IECEC, NASA glenn research center flywheel energy storage system development unit, 29 Jul., 2001.

[5] E. Lee, "A micro HTS renewable energy/attitude control system for micro/nano satellites," IEEE Trans. on Applied Superconductivity, vol. 13 , no. 2, June 2003.
[6] J. A. Kirk and P. A. Studer, "Mechanical Capacitor," NASA TND-8185, 1976.

[7] G. E. Rodriguez, P. A. Studer, and D. A. Baer, "Assessment of flywheel energy storage for spacecraft power systems," NASA Technical Memorandum, May 1983.

[8] J. M. Enrique, E. Dura'n, M. Sidrach-de-Cardona, and J. M. Andu' jar, "Theoretical assessment of the maximum power point tracking efficiency of photovoltaic facilities with different converter topologies,", Trans. on Solar Energy, Elsevier, 2006.

[9] J. A. Baroudi, V. Dinavahi, and A. M. Knight, "A review of power converter topologies for wind generators," Trans. on Renewable Energy, Elsevier, 2007.

[10] Tafticht, K. Agbossou, M. L. Doumbia, and A. Che' riti, “An improved maximum power point tracking method for photovoltaic systems," Trans. on Renewable Energy, Elsevier, 2007.

[11] N. Kasa, T. Iida, and L. Chen, "Flyback inverter controlled by sensorless current mppt for photovoltaic power system," IEEE Trans. on Industrial Electronics, vol. 52, no. 4, August 2005.

[12] W. D. Xiao, N. Ozog, and W. G. Dunford, "Topology study of photovoltaic interface formaximum power point tracking," IEEE Trans. on Industrial Electronics, vol. 54, no. 3, June 2007.

[13] J. L. Santos, F. Antunes, A. Chehab, and C. Cruz, "A maximum power point tracker for PV systems using a high performance boost converter," Trans. on Solar Energy, Elsevier, 2006.

[14] R. Gules, J. D. P. Pacheco, H. L. Hey, and J. Imhoff, “A maximum power point tracking system with parallel connection for PV stand-alone applications," IEEE Trans. on Industrial Electronics, vol. 55 , no. 7, July 2008.

[15] B. Abdi, J. Milimonfared, J. S. Moghani, and A. K. Kaviani, "Simplified design and optimization of slotless halbach machine for micro-satellite's electro-mechanical batteries," International Review of Electrical Engineering (I.R.E.E.), vol. 4, no. 2, April 2009.

[16] W. Wang, "Design of high speed flywheel motor/generator for aerospace applications," Ph.D. dissertation, The Pennsylvania State University, 2003.

[17] L. Parsa, "Performance improvement of permanent magnet AC motors," Ph.D. dissertation, Texas A\&M University, 2005.

[18] Selection of Electric Motor for Aerospace Applications, NASA, Preferred Reliability Practices, Practice, no. PD-ED-1229.

[19] A. Pressman, Switching Power Supply Design, 2nd ed. McGraw-Hill, 1998.

[20] Reliability Prediction of Electronic equipments, Military Handbook, MIL-HDBK-217, 1990.

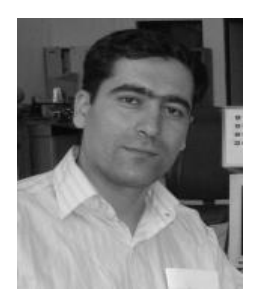

Babak Abdi was born in Tehran in 1976. He received his M.S. and Ph.D. degree in electrical engineering in 2005 and 2009 from Amirkabir University of Technology (Tehran Polytechnic), Tehran, Iran, respectively. He is currently a member of IEEE and a faculty member of Damavand branch, Islamic Azad University, Tehran, Iran. His research interests include power electronics, application of reliability in power electronics, Electromagnetic Interferences (EMI), and electrical machines and drives.

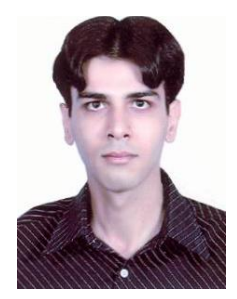

Sayyed Mohammad Mehdi Mirtalaei was born in Shahreza-Isfahan, Iran in 1983. He received his B.S. degree in electrical engineering from Isfan University of Technology, Iran in 2005. He received his M.S. and Ph.D. in electrical engineering from Amirkabir University of Technology, Tehran, Iran in 2007 and 2012 respectively. His research interest are power electronics, EMI/EMC and numerical method in electromagnetic.

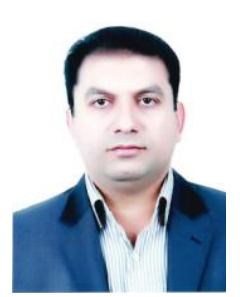

Reza Ghasemi was born in Tehran, Iran in 1979. He received his B.Sc. degree in Electrical engineering from Semnan University in 2000. He received the M.Sc. and the Ph.D. degree in control engineering from Amirkabir University of Technology, Tehran, Iran in 2004 and 2009, respectively. His research interests include large-Scale Systems, adaptive control, robust control, nonlinear control, and intelligent systems. Reza Ghasemi joined the Department of Electrical Engineering, Damavand Branch, Islamic Azad University, Tehran, Iran, where he is currently an assistant professor of electrical engineering. 